\title{
Preparation and properties of silicone rubber materials with foam/solid alternating multilayered structures
}

\author{
Wenhuan Zhang ${ }^{1,2} \cdot$ Zhaoping Deng $^{2} \cdot$ Hongwei Yuan ${ }^{1} \cdot$ Shikai Luo ${ }^{1} \cdot$ Huayin Wen ${ }^{1} \cdot$ Tao Liu $^{1}$
}

Received: 29 June 2020 / Revised: 6 September 2020 / Accepted: 3 October 2020 / Published online: 1 February 2021

(c) The Author(s) 2021. This article is published with open access

\begin{abstract}
In this paper, silicone rubber materials with foam/solid alternating multilayered structures were successfully constructed by combining the two methods of multilayered hot-pressing and supercritical carbon dioxide $\left(\mathrm{SCCO}_{2}\right)$ foaming. The cellular morphology and mechanical properties of the foam/solid alternating multilayered silicone rubber materials were systematically studied. The results show that the growth of the cell was restrained by the solid layer, resulting in a decrease in the cell size. In addition, the introduction of the solid layer effectively improved the mechanical properties of the microcellular silicone rubber foam. The tensile strength and compressive strength of the foam/solid alternating multilayered silicone rubber materials reached 5.39 and $1.08 \mathrm{MPa}$, which are $46.1 \%$ and $237.5 \%$ of the pure silicone rubber foam, respectively. Finite element analysis (FEA) was applied and the results indicate that the strength and proportion of the solid layer played important roles in the tensile strength of the foam/solid alternating multilayered silicone rubber materials. Moreover, the small cellular structures in silicone rubber foam can provided a high supporting counterforce during compression, meaning that the microcellular structure of silicone rubber foam improved the compressive property compared to that for the large cellular structure of silicone rubber foam.
\end{abstract}

\section{Introduction}

Silicone rubber foam is a porous polymer widely used in packaging, transportation, electronics, aerospace, and other fields [1-4]. It not only has the advantages of the high/low temperature resistance, aging resistance, radiation resistance, waterproofing, and biocompatibility of silicone rubber [5, 6], but also has the physical properties of low density, high elasticity, and abilities to absorb mechanical vibrations and impact excellently [7, 8]. However, it is difficult to control the cellular structure of silicone rubber foam by means of traditional preparation methods, resulting in poor mechanical properties. Hence, how to improve the mechanical properties of silicone rubber foam has become a focus of many scholars [9-11]. For example, Bai et al. [12] improved the cell

Tao Liu

liutao_caep@163.com

1 Institute of Chemical Materials, China Academy of Engineering Physics, Mianyang 621900, China

2 College of Materials and Chemistry and Chemical Engineering, Chengdu University of Technology, Chengdu 610059, China morphology and mechanical properties of microcell silicone rubber foam by adding nanometer graphite into the foam. Luo et al. [13] found that the cell size of the foam had a significant influence on the mechanical properties of silicone rubber foam materials. In addition, Xiang et al. [14] found that the microcellular and nanocellular structures played an important role in improving the mechanical properties of silicone rubber foam. Park et al. [15] found that the mechanical properties of silicone rubber foam can be improved by regulating its microstructure. Based on the existing research, the improvement of the mechanical properties of silicone rubber foam is still limited. Therefore, it is necessary to seek other ways to improve the mechanical properties of silicone rubber foam materials.

Materials with multilayered structures in nature such as shells, feathers, and butterfly wings have rich multilayered interfaces, alternating periodic arrangements and excellent mechanical properties. Inspired by multilayered structure, scholars have invented many molding methods to prepare multilayered polymeric composite materials. Micronano multilayer coextrusion technology [16-21] and layer-by-layer stacking technology [22] have mainly been studied. A multilayered structure can improve the barrier performance, acoustic absorption performance, electromagnetic shielding 
performance, mechanical strength, and puncture resistance. For example, Zhao et al. [23] successfully prepared polypropylene (PP) foam board with a foam/solid alternating multilayered structure through multilayered coextrusion technology, and found that the mechanical properties of the foam board with the foam/solid alternating multilayered structure were much higher than those of a pure PP foam board. Jiang et al. [24] prepared BT/NBR-PU foam materials with multilayered structures, and the BT/NBR-PU foam materials with multilayered structures had better sound absorption performance than the single materials. Zhou et al. [25] prepared PMMA multilayered microporous foam materials by means of laminated hot-pressing, and found that the regulation of the cellular morphology of the microporous foam improved. It can be seen from the above results that the construction of the foam/solid alternating multilayered structure in silicone rubber matrix may greatly improve the mechanical properties of silicone rubber foam materials. Within the scope of our knowledge, there are few reports on the research of multilayered silicone rubber foam materials.

In this work, silicone rubber materials with alternating multilayered structures were successfully constructed by stacking and supercritical fluid foaming. The cellular characteristics and mechanical properties of the foam/ solid alternating multilayered silicone rubber foam were systematically studied.

\section{Experimental methods}

\section{Materials}

Methyl vinyl silicone rubber (MVQ) with $0.13-0.2 \%$ vinyl (110-2) is purchased from Chengdu Zhonglan Chengguang Chemical Research Institute Co, Ltd. (China). The molecular weight of silicone rubber ranges from $\sim 450,000-700,000$. Fumed silica (AS-200, specific surface area is $200 \pm 20 \mathrm{~m}^{2} / \mathrm{g}$ ) is supplied by Shenyang Chemical Co, Ltd. (China). Hydroxyl silicone oil (GY-209-3) was purchased from Zhonghao Chengguang Chemical Research Institute (China). Disopropyl peroxide (DCP) is purchased from Chengdu Kelong Chemical Reagent Factory (China). High purity $\mathrm{CO}_{2}(99.999 \%)$ is purchased from Sichuan Runtai Special Gas Co, Ltd. (China).

\section{Preparation of silicone rubber with a foam/solid alternating multilayered structure}

The formula in Table 1 is used to prepare silicone rubber mixture, and a mixer (PolyLab OS-RheoDrive 7, HAAKE, Germany) is used to mix the materials. The temperature is $105^{\circ} \mathrm{C}$ and the rotation speed is $90 \mathrm{r} / \mathrm{min}$. First, silicone rubber, hydroxyl silicone oil, and silica are blended for 25 min. After that, silicone rubber mixture is removed and the
Table 1 The formulas for the silicone rubber sample

\begin{tabular}{lllll}
\hline Sample & $\begin{array}{l}\text { MVQ } \\
(110-2)\end{array}$ & $\begin{array}{l}\text { Fumed } \\
\text { silica } \\
\text { (AS-200) } \\
\text { phr }\end{array}$ & $\begin{array}{l}\text { Hydroxyl } \\
\text { silicone oil } \\
\text { (GY-209-3) } \\
\text { phr }\end{array}$ & Curatives (DCP) \\
\hline $\mathrm{A}_{1}$ & 100 & 40 & 1 & 2 \\
$\mathrm{~A}_{2}$ & 100 & 40 & 3 & 2 \\
$\mathrm{~A}_{3}$ & 100 & 40 & 5 & 2 \\
$\mathrm{~A}_{4}$ & 100 & 40 & 7 & 2 \\
\hline
\end{tabular}

mixer again for $25 \mathrm{~min}$. After cooling to room temperature, silicone rubber mixture is mixed with the vulcanizing agent in the mixer. Finally, the mixed silicone rubber is applied to the preparation of foam/solid alternating multilayered silicone rubber foam materials after being held at room temperature for $24 \mathrm{~h}$.

Figure 1 shows the preparation process for the foam/solid alternating multilayered silicone rubber foam materials. First, the samples in Table 1 are made into sheets with a thickness of $0.2 \mathrm{~mm}$. The samples are cut into $30 \mathrm{~mm} \times 40 \mathrm{~mm}$ sheets, according to the size of the mold. Then, sample $A_{1}$ is alternately stacked with the sheets from the samples $A_{2}, A_{3}$, and $\mathrm{A}_{4}$. Different alternating multilayered silicone rubber foam samples are constructed according to Table 2 . The sample is placed in a mold $(30 \mathrm{~mm} \times 40 \mathrm{~mm} \times 2 \mathrm{~mm})$ and pressed by a flat vulcanizer (Laboratory platen press, P300E) for $10 \mathrm{~min}$ at room temperature. After that, the samples are prevulcanized for $10 \mathrm{~min}$ at $125^{\circ} \mathrm{C}$ by the flat vulcanizer to prepare alternating multilayered silicone rubber.

The prevulcanized alternating multilayered silicon rubber sheet is cut into sample strips with dimensions of $10 \mathrm{~mm} \times 30$ $\mathrm{mm}$. $\mathrm{SCCO}_{2}$ is used as the foaming agent, and supercritical fluid foaming equipment is used to produce silicone rubber foam according to the process in Table 2. The pressureholding time is $30 \mathrm{~min}$. Then, the kettle is quickly decompressed within $2 \mathrm{~s}$, and the sample strip is removed and placed in an air-circulating oven at $160{ }^{\circ} \mathrm{C}$ for $30 \mathrm{~min}$ to full vulcanization. Finally, the sample is removed and placed in the aircirculating oven at $190^{\circ} \mathrm{C}$ for $60 \mathrm{~min}$ for heat treatment to obtain foam/solid alternating multilayered silicone rubber foam materials.

\section{Characterization}

\section{Analysis of the apparent density}

The apparent density of the sample is measured by a Vernier caliper and analytical balance. The density of the foam layer is computed by using a two-phase model [26].

$\rho_{\text {foam }}=\frac{\rho_{\text {solid }} \rho X_{\text {foam }}}{\rho_{\text {solid }}-\rho X_{\text {solid }}}$, 
Fig. 1 Schematic diagram of the preparation process of foam/ solid alternating multilayered silicone rubber

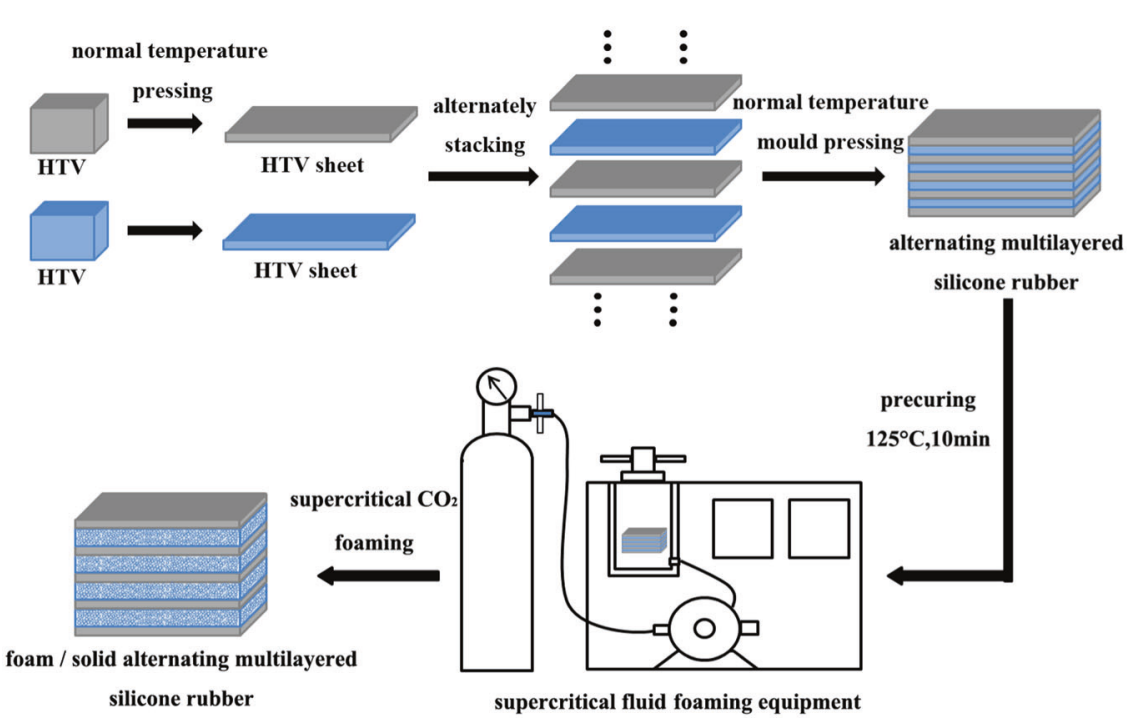

Table 2 Preparation of the foam/solid alternating multilayered silicone rubber materials

\begin{tabular}{|c|c|c|c|c|c|}
\hline Sample & $\begin{array}{l}\text { The } \\
\text { foam layer } \\
\text { - }\end{array}$ & & $\begin{array}{l}\text { The } \\
\text { solid layer } \\
\text { - }\end{array}$ & $\begin{array}{l}\text { Saturation } \\
\text { pressure } \\
\mathrm{MPa}\end{array}$ & $\begin{array}{l}\text { Saturation } \\
\text { temperature } \\
{ }^{\circ} \mathrm{C}\end{array}$ \\
\hline$S_{1}$ & & $\mathrm{~A}_{1}$ & & 16 & 50 \\
\hline $\mathrm{S}_{2}$ & & $\mathrm{~A}_{2}$ & & 16 & 50 \\
\hline $\mathrm{S}_{3}$ & & $\mathrm{~A}_{3}$ & & 16 & 50 \\
\hline $\mathrm{S}_{4}$ & & $\mathrm{~A}_{4}$ & & 16 & 50 \\
\hline $\mathrm{S}_{5}$ & $\mathrm{~A}_{2}$ & & $\mathrm{~A}_{1}$ & 16 & 50 \\
\hline$S_{6}$ & $\mathrm{~A}_{3}$ & & $\mathrm{~A}_{1}$ & 16 & 50 \\
\hline$S_{7}$ & $\mathrm{~A}_{4}$ & & $\mathrm{~A}_{1}$ & 16 & 50 \\
\hline $\mathrm{S}_{8}$ & $\mathrm{~A}_{4}$ & & $\mathrm{~A}_{1}$ & 12 & 50 \\
\hline $\mathrm{S}_{9}$ & $\mathrm{~A}_{4}$ & & $\mathrm{~A}_{1}$ & 14 & 50 \\
\hline$S_{10}$ & $\mathrm{~A}_{4}$ & & $\mathrm{~A}_{1}$ & 18 & 50 \\
\hline$S_{11}$ & $\mathrm{~A}_{4}$ & & $\mathrm{~A}_{1}$ & 16 & 40 \\
\hline$S_{12}$ & $\mathrm{~A}_{4}$ & & $\mathrm{~A}_{1}$ & 16 & 60 \\
\hline$S_{13}$ & $\mathrm{~A}_{4}$ & & $\mathrm{~A}_{1}$ & 16 & 70 \\
\hline $\mathrm{S}_{14}$ & & $\mathrm{~A}_{4}$ & & 12 & 50 \\
\hline
\end{tabular}

$X_{\text {solid }}=\frac{d_{\text {solid }}}{d}$,

$X_{\text {foam }}=1-\frac{d_{\text {solid }}}{d}$,

where $\rho_{\text {foam }}$ is the density of the foam layer, $\rho_{\text {soild }}$ is the density of the solid layer, $\rho$ is the density of the alternating layers of the foam/solid silicone rubber foam materials, $X_{\text {foam }}$ is the volume fraction of the foam layer, $X_{\text {solid }}$ is the volume fraction of the solid layer, $d$ is the thickness of the foam sample, $d_{\text {solid }}$ is the total thickness of the solid layer in the scanning electron microscopy (SEM) images.

\section{Analysis of the cellular morphology and layer structure}

A field emission scanning electron microscope (SIGMA 300, Zeiss, Germany) is used to observe the cellular structures and alternating multilayered structure of silicone rubber foam. The sample is first soaked in liquid nitrogen for $5 \mathrm{~min}$, then a section of the sample is sprayed with gold, and this section of the sample is observed by SEM. Image $\mathbf{J}$ software used to analyze the SEM images and obtain the cell size of the samples. The following formula is used to calculate the cell density $N_{f}\left(\right.$ cells $\left./ \mathrm{cm}^{3}\right)$.

$N_{f}=\left(\frac{n}{A}\right)^{\frac{3}{2}}$,

where $n$ is the number of cells in the SEM image of silicone rubber foam section, and $A$ is the area of the SEM image $\left(\mathrm{cm}^{2}\right)$.

\section{Rheological property test}

A rubber processing analyzer (RPA2000, ALPHA, America) is used to test silicone rubber mixture. The test temperature is $165^{\circ} \mathrm{C}$ and the test time is $60 \mathrm{~min}$. The energy storage modulus $\left(G^{\prime}\right)$, loss modulus $\left(G^{\prime \prime}\right)$ and viscosity $\left(\eta^{*}\right)$ changes over time during the silicone rubber mixture vulcanization process.

\section{Mechanical performance}

The tensile and compression properties of the foam/solid alternating multilayered silicone rubber foam are tested by a solid rheology analyzer (RSA G2, TA, America). The tensile test samples are cut into dumbbell samples with a length of $20 \pm 0.5 \mathrm{~mm}$, a width of $5 \pm 0.1 \mathrm{~mm}$, and a thickness of $2 \pm 0.5 \mathrm{~mm}$. The tensile rate during 
Fig. 2 The effect of the hydroxyl silicone oil content on the $G^{\prime}$, $G^{\prime \prime}$, and $\eta^{*}$ of the silicone rubber. A Storage modulus, $\mathbf{B}$ loss modulus, and $\mathbf{C}$ viscosity. Hydroxyl silicone oil content: $\mathrm{A}_{1}-1 \mathrm{phr}, \mathrm{A}_{2}-3 \mathrm{phr}, \mathrm{A}_{3}-5 \mathrm{phr}$, and $\mathrm{A}_{4}-7 \mathrm{phr}$
(A)

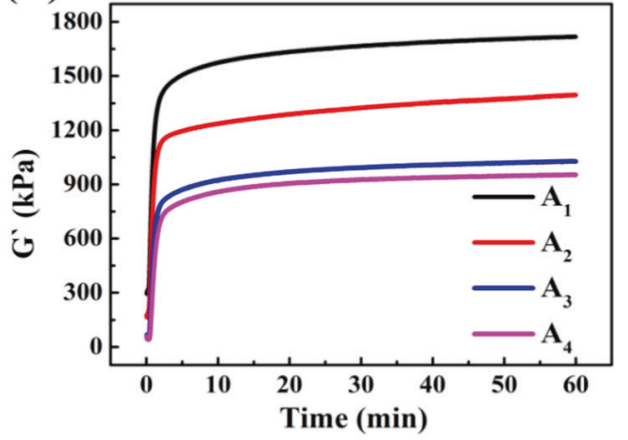

(B)

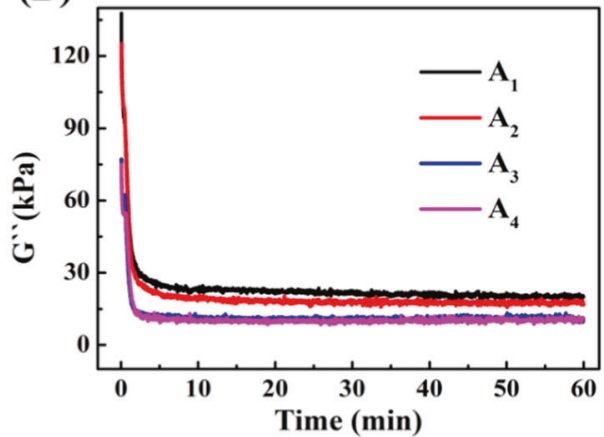

(C)

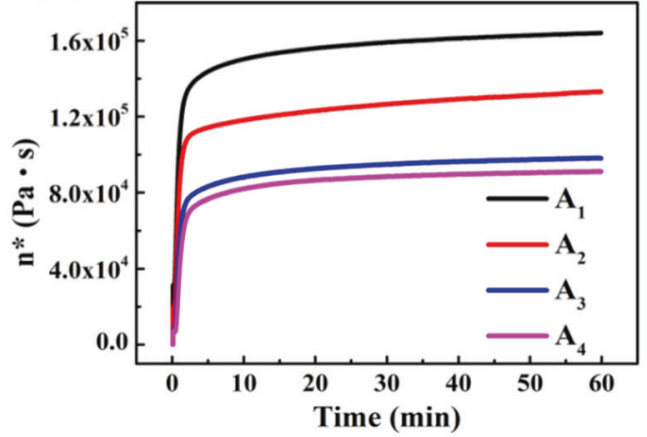

the test is $3.33 \mathrm{~mm} / \mathrm{s}$. The compression test samples are cut into a cylinder with a diameter of $5 \mathrm{~mm}$ and a thickness of $2 \pm 0.5 \mathrm{~mm}$. The compression rate during the test is $0.083 \mathrm{~mm} / \mathrm{s}$.

\section{Finite element analysis (FEA)}

A numerical two-dimensional plane strain mode in silicone rubber foam is designed. The model dimension is $200 \times$ $200 \mu \mathrm{m}$. Circular voids are distributed uniformly with a radius from 2.5 to $50 \mu \mathrm{m}$ and the void fraction is set at $54.0 \%$. The Mooney-Rivlin constitutive model is adapted for the silicone rubber. The boundary conditions are as follows: the bottom is constrained, both the left and right sides are free, the loading is from the upper side, and the compressive rate is set at $15.0 \%$. Then, the supporting counterforce of the cell is calculated by ANSYS software which is based on the finite element method [27].

A linear elastic model of the uniaxial tensile test curves from the experimental materials is used for qualitative analysis. A three-dimensional finite element model of the foam/solid alternating multilayered silicone rubber is designed. Three-dimensional finite element analysis is used to study the stress distribution and tensile strength of the samples with different layered structures. The size of the model is $57 \times 15 \times 3 \mathrm{~mm}$. The vertical displacement is $57 \mathrm{~mm}$ (strain is $100 \%$ ), and the stress distribution and tensile load are analyzed.

\section{Results and discussion}

\section{Basis of the foam/solid alternating multilayered silicone rubber foam}

Figure 2 shows the effect of the hydroxyl silicone oil content on the storage modulus $\left(G^{\prime}\right)$, the loss modulus $\left(G^{\prime \prime}\right)$, and the viscosity $\left(\eta^{*}\right)$ of silicone rubber. During the whole process of vulcanization, the content of hydroxyl silicone oil, and the $G^{\prime}, G^{\prime \prime}$, and $\eta^{*}$ values for the silicone rubber materials gradually decrease. $G^{\prime}$ is essentially the elastic modulus, which is an index of the rebound after deformation. The larger $G^{\prime}$ is, the easier it is to recover after deformation. However, the loss modulus and viscosity reflect the deformation ability. As shown Fig. 2, the $G^{\prime}, G$ ", and $\eta^{*}$ of sample $\mathrm{A}_{1}$ are highest among all other samples, which is not conducive to the growth and formation of cells during foaming process. Arefmanesh and Advarn et al. $[28,29]$ investigated the growth process of diffusioncontrolled cells in a viscous fluid, and found that the greater the viscosity of silicone rubber substrate is, the greater the resistance to cell growth. The stress of the elastic energy acting on the cellular interface prevent the cell from growing and promotes cell shrinkage during the cellular shaping stage. During supercritical fluid foaming, the elastoplasticity of silicone rubber matrix plays an important role in controlling the microcellular structure [30]. Hence, the above analysis conclusion is the basis for the construction of the 
Fig. 3 SEM images of the microcellular silicone rubber foam with different silicon oil contents (saturation pressure: $16 \mathrm{MPa}$, saturation temperature: $50{ }^{\circ} \mathrm{C}$ )
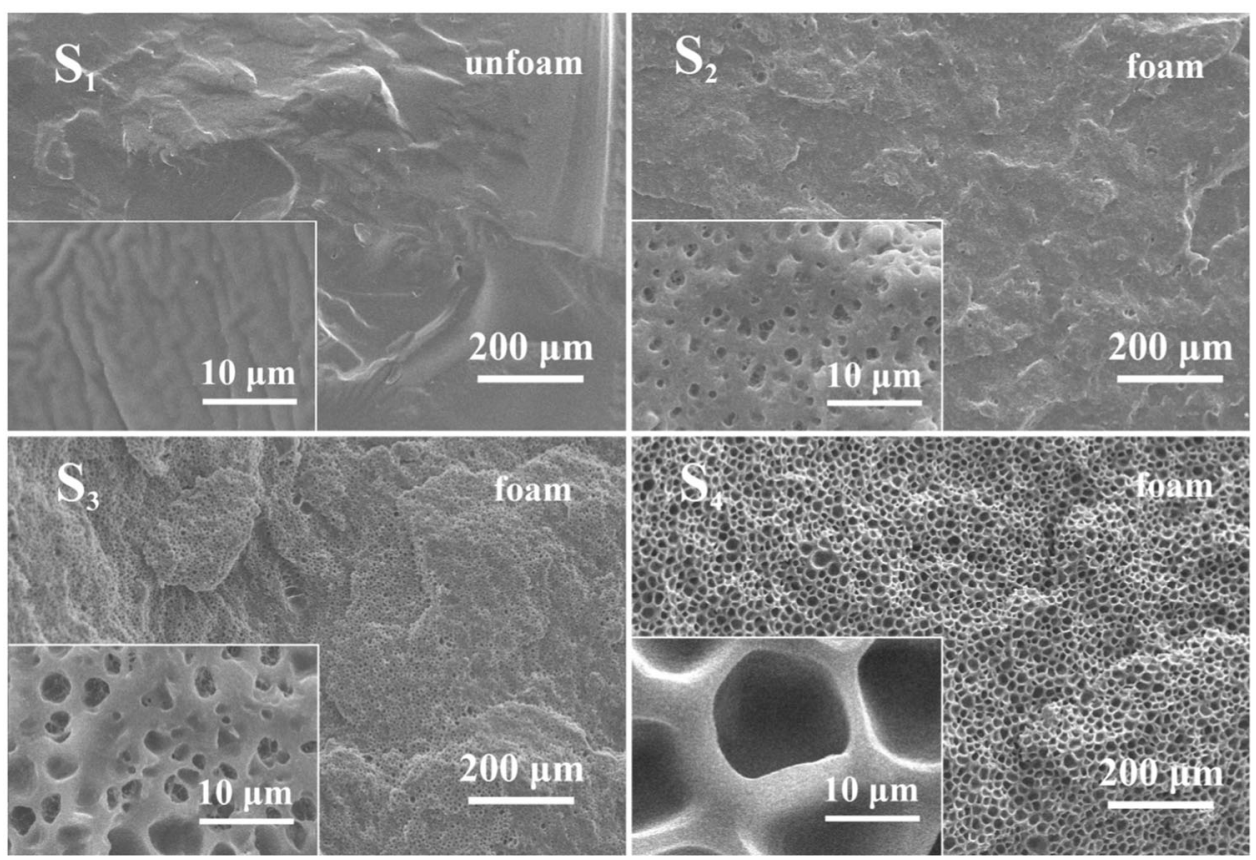

foam/solid alternating multilayered silicone rubber foam materials.

\section{Cellular morphology of the foam/solid alternating multilayered silicone rubber foam}

\section{Construction of the alternating multilayered foam/solid silicone rubber foam}

Figure 3 shows the influence of the silicone oil content on the cellular morphology of the silicone rubber foam. Table 3 shows the density, cell size, and cell density statistics of the samples. According to Fig. $3\left(\mathrm{~S}_{1}\right)$ and Table 3, one can see that the cells are not present in silicone rubber matrix when the silicone oil content is 1 phr. As the silicone oil content exceeds $3 \mathrm{phr}$, cells appears in silicone rubber matrix. Moreover, with increasing silicone oil content, the cell size of the microcellular silicone rubber foam increases, but the cell density decreases. This is because in the prevulcanized silicone rubber matrix, the partial vulcanized silicone rubber matrix exhibits elasticity, while the unvulcanized silicone rubber matrix shows plasticity. The silicone oil has a plasticizing effect on the silicone rubber matrix. Hence, when the content of silicone oil is low, the prevulcanized silicone rubber matrix has an increased elasticity. During foaming, elastic shrinkage occurs in the silicone rubber foam, leading to the reduction in the cell size or even a disappearance of the cellular structure. When the content of silicone oil is high, the prevulcanized silicone rubber matrix retains great plasticity. Therefore, silicone rubber matrix can retain the microcellular structure, which results in the formation of microcellular silicone rubber foam.

Figure 4 shows the cellular morphology of the foam/solid alternating multilayered silicone rubber materials. From Fig. $4\left(\mathrm{~S}_{5}\right)$, it can be seen that when the silicone oil content ratio of the foam layer and solid layer is 3 to 1 , a foam/solid alternating multilayered structure cannot be obtained, and cracks appear in the sample. When the silicone oil content ratio of the foam layer and solid layer exceeds 5 to 1 , foam/ solid alternating multilayered silicone rubber materials are successfully built $\left(S_{6}\right.$ and $\left.S_{7}\right)$. The interface between the foam layer and solid layer is continuous and dose not crack. The solid layer is flat, and the foam layer has dense and uniform cells, which is an obvious closed-cell foam. Table 3 shows that under the same foaming conditions, the cell size in the foam/solid alternating multilayered silicone rubber foam is significantly smaller than that in the pure silicone rubber foam, and its cell density is higher than that in the pure silicone rubber foam. In addition, the average cell size of the foam/solid alternating multilayered silicone rubber material $\left(\mathrm{S}_{7}\right)$ is $3.98 \mu \mathrm{m}$, which decreases to $14.23 \mu \mathrm{m}$ compared with that of the pure silicone rubber foam $\left(\mathrm{S}_{4}\right)$. The cell density of the foam layer is $6.82 \times 10^{9}$ cells $/ \mathrm{cm}^{3}$, which is much higher than that of the pure silicone rubber foam $\left(\mathrm{S}_{4}, 1.75 \times 10^{8}\right.$ cells $\left./ \mathrm{cm}^{3}\right)$. This may be due to two reasons: on the one hand, the solid layer restricts the cellular growth in the foam layer as shown in Fig. 5. On the other hand, the solid layer squeezes the foam layer during the formation of the cellular structure, which promotes the shrinkage of the foam layer. These two reasons result in a 
Table 3 Density, cell size, and cell density of the silicone rubber materials
Fig. 4 SEM images of the foam/ solid alternating multilayered silicone rubber foam (saturation pressure: $16 \mathrm{MPa}$, saturation temperature: $50{ }^{\circ} \mathrm{C}$ )

\begin{tabular}{lllll}
\hline Sample & $\begin{array}{l}\text { Density } \\
\left(\mathrm{g} / \mathrm{cm}^{3}\right)\end{array}$ & $\begin{array}{l}\text { Density of the foam layer } \\
\left(\mathrm{g} / \mathrm{cm}^{3}\right)\end{array}$ & $\begin{array}{l}\text { Cell size } \\
\mu \mathrm{m}\end{array}$ & $\begin{array}{l}\text { Cell density } \\
\left(\mathrm{cells} / \mathrm{cm}^{3}\right)\end{array}$ \\
\hline $\mathrm{S}_{1}$ & $1.21 \pm 1.5 \times 10^{-3}$ & - & - & - \\
$\mathrm{S}_{2}$ & $1.20 \pm 3.1 \times 10^{-3}$ & - & $0.67 \pm 0.21$ & $3.15 \times 10^{10} \pm 5.4 \times 10^{-9}$ \\
$\mathrm{~S}_{3}$ & $0.87 \pm 1.1 \times 10^{-2}$ & - & $2.99 \pm 0.56$ & $1.32 \times 10^{10} \pm 1.8 \times 10^{-9}$ \\
$\mathrm{~S}_{4}$ & $0.61 \pm 5.6 \times 10^{-2}$ & - & $18.21 \pm 1.13$ & $1.75 \times 10^{8} \pm 2.0 \times 10^{-7}$ \\
$\mathrm{~S}_{5}$ & $1.20 \pm 1.6 \times 10^{-3}$ & - & - & - \\
$\mathrm{S}_{6}$ & $0.97 \pm 9.5 \times 10^{-3}$ & $0.75 \pm 7.6 \times 10^{-3}$ & $1.71 \pm 0.11$ & $1.08 \times 10^{10} \pm 6.2 \times 10^{-8}$ \\
$\mathrm{~S}_{7}$ & $0.86 \pm 6.1 \times 10^{-2}$ & $0.69 \pm 1.1 \times 10^{-2}$ & $3.98 \pm 0.43$ & $6.82 \times 10^{9} \pm 4.8 \times 10^{8}$ \\
$\mathrm{~S}_{8}$ & $0.77 \pm 1.2 \times 10^{-2}$ & $0.60 \pm 5.2 \times 10^{-3}$ & $13.42 \pm 1.17$ & $1.89 \times 10^{8} \pm 2.2 \times 10^{7}$ \\
$\mathrm{~S}_{9}$ & $0.79 \pm 3.4 \times 10^{-2}$ & $0.62 \pm 4.9 \times 10^{-3}$ & $5.70 \pm 0.41$ & $1.17 \times 10^{9} \pm 8.8 \times 10^{6}$ \\
$\mathrm{~S}_{10}$ & $0.92 \pm 4.2 \times 10^{-2}$ & $0.71 \pm 7.6 \times 10^{-3}$ & $2.30 \pm 0.35$ & $1.44 \times 10^{10} \pm 1.9 \times 10^{-8}$ \\
$\mathrm{~S}_{11}$ & $1.03 \pm 8.1 \times 10^{-3}$ & $0.83 \pm 4.1 \times 10^{-3}$ & $0.92 \pm 0.19$ & $2.64 \times 10^{10} \pm 9.2 \times 10^{-9}$ \\
$\mathrm{~S}_{12}$ & $0.82 \pm 1.8 \times 10^{-2}$ & $0.66 \pm 2.7 \times 10^{-2}$ & $7.65 \pm 0.48$ & $2.45 \times 10^{9} \pm 1.7 \times 10^{8}$ \\
$\mathrm{~S}_{13}$ & $0.80 \pm 3.5 \times 10^{-2}$ & $0.62 \pm 3.3 \times 10^{-2}$ & $11.87 \pm 2.09$ & $8.18 \times 10^{8} \pm 2.2 \times 10^{7}$ \\
$\mathrm{~S}_{14}$ & $0.57 \pm 4.1 \times 10^{-2}$ & - & $73.38 \pm 3.45$ & $8.74 \times 10^{5} \pm 7.3 \times 10^{4}$ \\
\hline
\end{tabular}
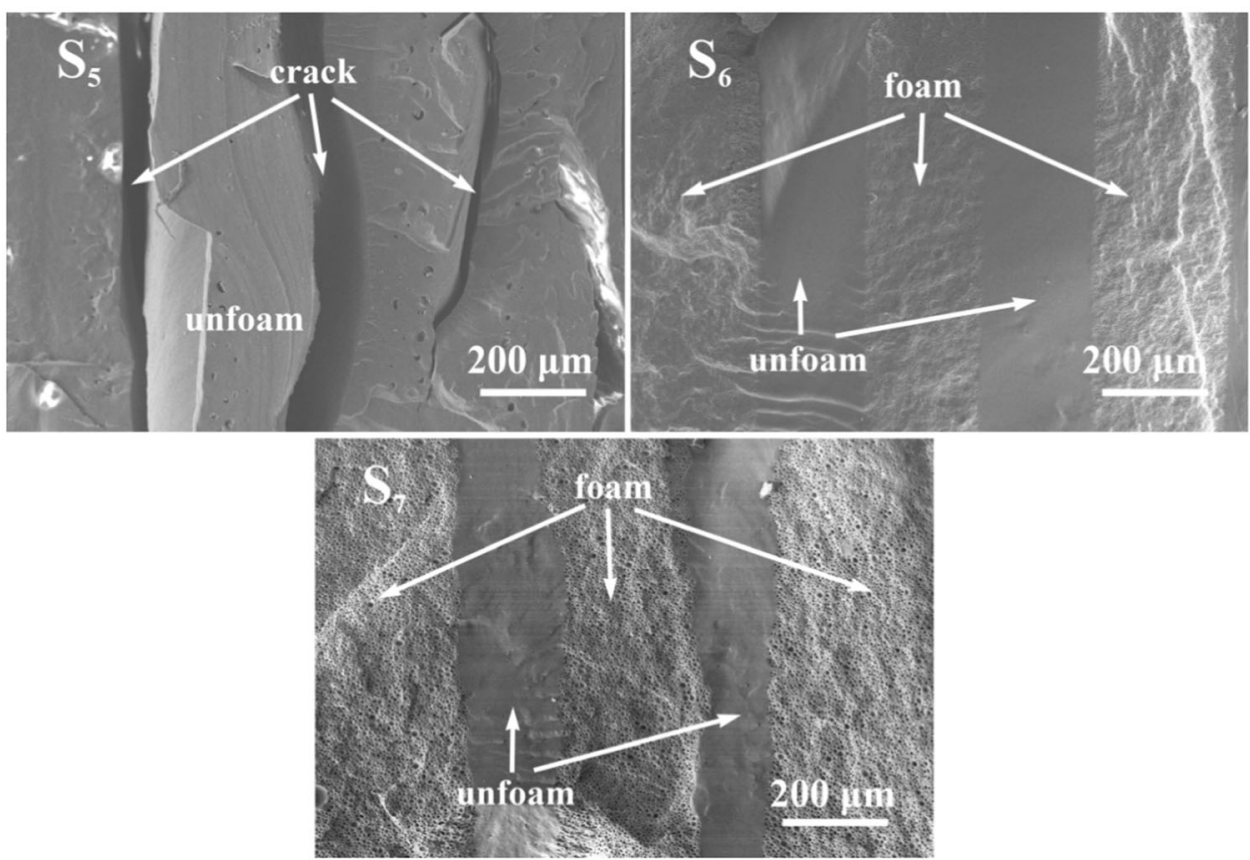

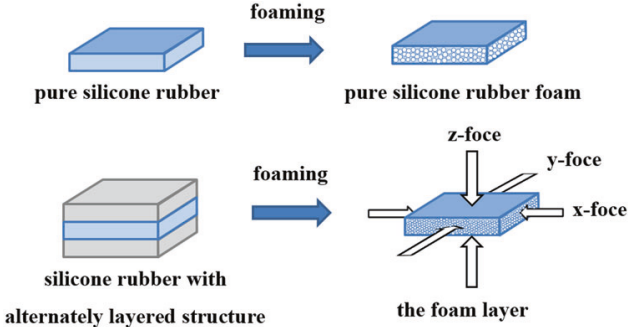

Fig. 5 Diagrammatic sketch of the solid layer restricting the cellular growth of the foam layer decreased cell size and increased cell density in the alternating multilayered silicone rubber foam.

\section{Effect of the saturation pressure on the cellular morphology of the foam/solid alternating multilayered silicone rubber foam}

Figure 6 shows the effect of the saturation pressure on the cellular morphology of the foam/solid alternating multilayered silicone rubber foam. As shown in Fig. 6 and Table 3, with increasing saturation pressure, the average 
Fig. 6 SEM images of the alternating multilayered silicone rubber (9L) at different saturation pressures (saturation temperature: $50{ }^{\circ} \mathrm{C}$ )
Fig. 7 SEM images of the foam/ solid alternating multilayered silicone rubber (9L) at different saturation temperatures (saturation pressure: 16 MPa)
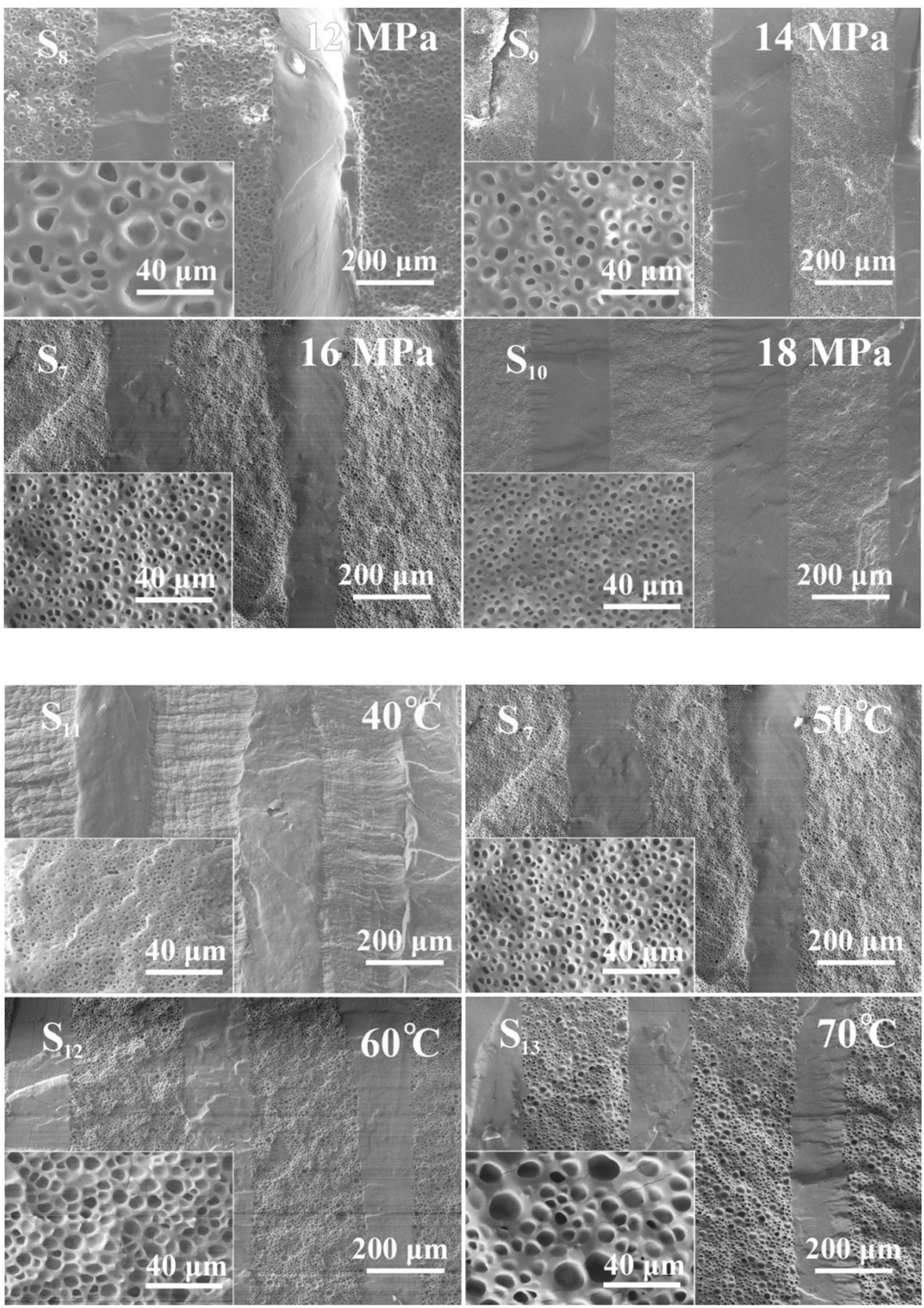

cell size of the foam/solid alternating multilayered silicone rubber foam gradually decreases, and the cell density gradually increases. When the saturation pressure is $18 \mathrm{MPa}$, the cell size of the sample $\left(\mathrm{S}_{10}\right)$ reaches $2.3 \mu \mathrm{m}$, and the cell density reaches $1.44 \times 10^{10}$ cells $/ \mathrm{cm}^{3}$. According to the classical nucleation theory [31-33], the higher the saturation pressure is, the larger the nucleation rate. Therefore, with an increase in the saturation pressure, the cell size of the foam/solid alternating layers of silicone rubber foam gradually decreases, and the cell density of the foam/solid alternating multilayered silicone rubber foam gradually increases.

\section{Effect of the saturation temperature on the cellular morphology of the foam/solid alternating multilayered silicone rubber foam}

Figure 7 shows the effect of the saturation temperature on the cellular morphology of the foam/solid alternating multilayered silicone rubber foam. From Fig. 7 and Table 3, one 
Fig. 8 Tensile strength comparison of alternating multilayered silicone rubbers with that of pure solid silicone rubber and pure foam. The content ratios of the solid layer and the foam layer are $\mathbf{A} 1: 3$, B 1:5, and C 1:7
(A)

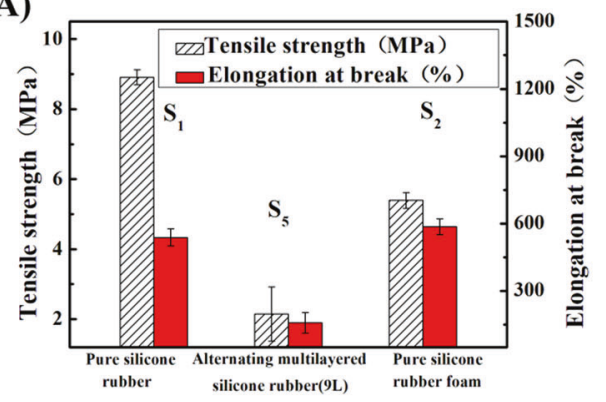

(B)

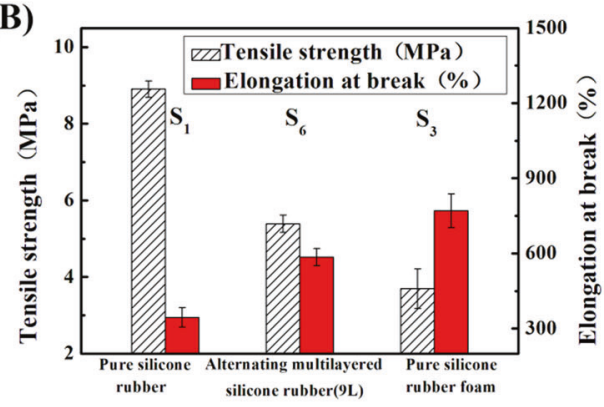

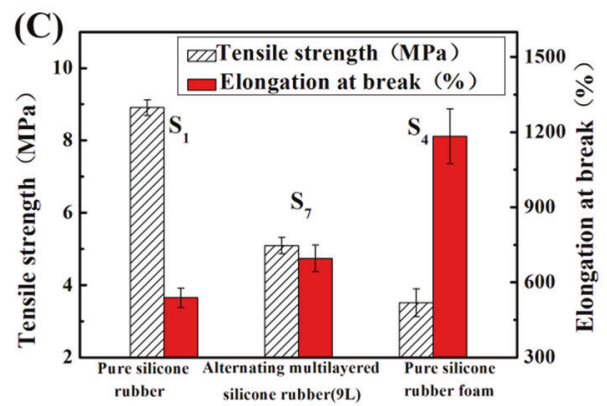

can see that with an increase in the saturation temperature, the average cell size gradually increases, and the cell density gradually decreases. When the saturation temperature is $40{ }^{\circ} \mathrm{C}$, the cell size of the sample $\left(\mathrm{S}_{11}\right)$ reaches $0.92 \mu \mathrm{m}$, and the cell density reaches $2.64 \times 10^{10}$ cells $/ \mathrm{cm}^{3}$. The result is attributed to three reasons: first, the higher the saturation temperature is, the greater the nucleation barrier, which leads to a reduction in the nucleation rate. The second one is that with an increase in the saturation temperature, the content of carbon dioxide entering silicone rubber matrix decreases, leading to a reduction in the nucleation rate. Finally, the cells are more likely to coalesce because the strength of silicone rubber matrix decreases when the saturation temperature increases. The phenomenon is consistent with the conclusions reached by Hong and Lee [34] and Yang et al. [35].

\section{Mechanical properties of the foam/solid alternating multilayered silicone rubber foam}

\section{The effect of the cellular structure on the tensile properties of silicone rubber materials}

Figure 8 shows the influence of the different structures on the tensile properties of silicone rubber materials. Figure 8 shows that the tensile strength of the solid silicone rubber is 8.91 MPa $\left(\mathrm{S}_{1}\right)$, and the tensile strength of the foam/solid alternating multilayered silicone rubber foam is significantly improved by means of the introduction of a solid layer. The tensile strength of the pure silicone rubber foam materials reaches $3.69 \mathrm{MPa}\left(\mathrm{S}_{3}\right)$ and $3.52 \mathrm{MPa}\left(\mathrm{S}_{4}\right)$, and the tensile strength of the foam/solid alternating multilayered silicone rubber foam reaches $5.39 \mathrm{MPa}\left(\mathrm{S}_{6}\right)$ and $5.09 \mathrm{MPa}\left(\mathrm{S}_{7}\right)$, which are $46.07 \%$ and $44.6 \%$ higher than that of $\left(\mathrm{S}_{3}\right)$ and $\left(\mathrm{S}_{4}\right)$, respectively. In addition, the elongation at break of the foam/solid alternative multilayered silicone rubber foam reaches $585.91 \%\left(\mathrm{~S}_{6}\right)$ and $696.06 \%\left(\mathrm{~S}_{7}\right)$, indicating that the solid layer can retain a high elongation at break in the pure silicone rubber foam. Compared with that break of the pure solid silicone rubber materials, the elongation at break of sample $S_{6}$ and sample $S_{7}$ are improved by $70.13 \%$ and $102.12 \%$, respectively, which indicates an increased tensile deformation. However, the tensile strength and elongation at break of sample $\mathrm{S}_{5}$ are both relatively low. According to Fig. 4, this is because when the viscosity difference between the foam layer and the solid layer is relatively small, crack defects are likely to form at the layer interface, resulting in poor mechanical properties.

Figure 9 shows the influence of the foaming parameters on the tensile properties of the foam/solid alternating multilayered silicone rubber foam materials. According to Fig. 9A, when the saturation pressure increases from 12 to $18 \mathrm{MPa}$, the tensile strength and elongation at break of the foam/solid alternating multilayered silicone rubber increase from 3.88 to $5.25 \mathrm{MPa}$, and $416.09 \%$ to $699.28 \%$, respectively. This is because the saturation pressure mainly affects the cell size and cell density of the foam layer. The higher the foam pressure is, the smaller the cell size. Therefore, a sample with a small cell size can exhibit improved mechanical properties [36]. In addition, with an increase in the cell size, defects form at the interface, which leads to a reduction in the mechanical properties. From Fig. 9B, when the saturation temperature increases from 40 to $70{ }^{\circ} \mathrm{C}$, the tensile strength and elongation at break of the foam/solid 
Fig. 9 The effect of the foaming parameters on the tensile properties of the alternating multilayered silicone rubber (9L): A pressure and B temperature
(A)

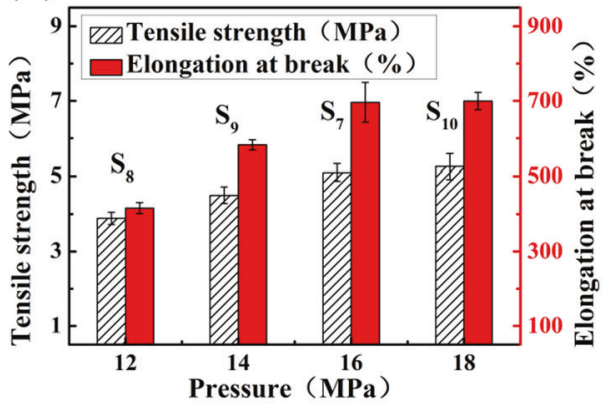

(B)

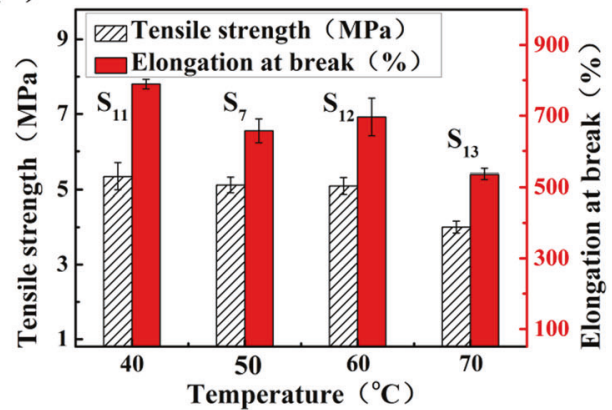

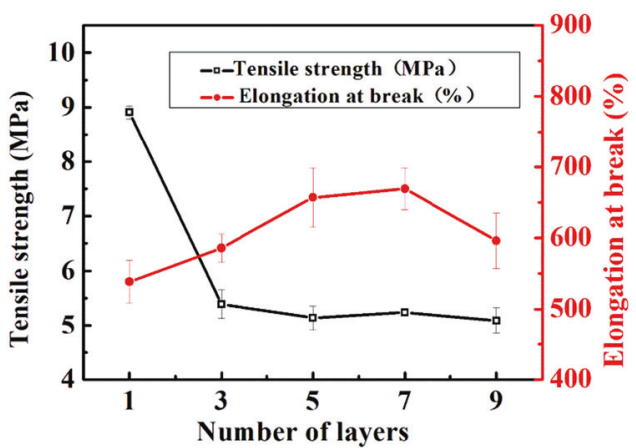

Fig. 10 The tensile properties of foam/solid alternating multilayered silicone rubber foam materials with different numbers of layers

alternating multilayered silicone rubber materials decrease from 5.34 to $4.01 \mathrm{MPa}$, and $789.22 \%$ to $536.16 \%$, respectively. With increasing saturation temperature, the cell size of the foam/solid alternating multilayered silicone rubber foam gradually increases, indicating that the mechanical properties of the foam/solid alternating multilayered silicone rubber foam materials decrease.

The effect of the number of layers on the tensile properties is shown in Fig. 10. When the number of layers increases to 3, the tensile strength of the foam/solid alternating multilayered silicone rubber foam decreases sharply to $5.39 \mathrm{MPa}$. With an increase in the number of layers, the tensile strength of the foam/solid alternating multilayered silicone rubber foam decreases slightly, but the tensile strength of all samples is higher than $5 \mathrm{MPa}$. To better understand the effect of the alternating multilayered structure on the tensile properties of the foam/solid alternating multilayered silicone rubber foam, we analyze the results by theoretical analysis and finite element simulation.

The stress of the solid layer and the foam layer can be expressed as follows:

$\sigma_{1 f s}=\sigma_{1}\left(\varepsilon_{1}\right)=E_{1} \varepsilon_{1}$,
$\sigma_{2 f s}=\sigma_{2}\left(\varepsilon_{2}\right)=E_{2} \varepsilon_{2}$, where $\sigma_{1 f s}$ is the fracture stress of the solid layer, $\sigma_{2 f s}$ is the fracture stress of the foam layer, $\varepsilon_{1}$ is the fracture strain of the solid layer, $\varepsilon_{2}$ is the fracture strain of the foam layer, $E_{1}$ is the elastic modulus of the solid layer, and $E_{2}$ is the elastic modulus of the foam layer. From the above study, $\sigma_{1}$ is higher than $\sigma_{2}$ but $\varepsilon_{2}$ is higher than $\varepsilon_{1}$. According to the parallel model, it is assumed that the fracture strain is the same during the tensile process as follows:

$\varepsilon=\varepsilon_{1}=\varepsilon_{2}$,

where $\varepsilon$ is the fracture strain of the foam/solid alternating multilayered silicone rubber foam. Hence, the stress of the foam/solid alternating multilayered silicone rubber foam can be expressed as:

$\sigma=\eta \sigma_{1 f s}+(1-\eta) \sigma_{2}\left(\varepsilon_{1}\right)$,

where $\sigma$ is the fracture stress of the foam/solid alternating multilayered silicone rubber foam, and $\eta$ is the proportion of the solid layer thickness.

In addition, finite element analysis is used to analyze the stress of the samples according to the equivalent modulus of the elasticity, which can be expressed as:

$\sigma=\left[\eta E_{1}+(1-\eta) E_{2}\right] \varepsilon$.

When a fracture forms, the fracture strain is the same, i.e., $\varepsilon=\varepsilon_{1}=\varepsilon_{2}$. The above equation can be expressed as:

$\sigma=\eta \sigma_{1}+(1-\eta) E_{2} \varepsilon_{1}$.

The stress distribution of the samples is shown in Fig. 11. In this study, it is assumed that the strain is the same, so there is no significant change in the stress distribution. Figure 12 shows that the theoretical analysis and simulation results are essentially the same. With an increase in the number of layer, the tensile strength of the foam/solid alternating multilayered silicone rubber foam decreases, indicating that the tensile strength of the foam/solid alternating multilayered silicone rubber foam mainly depends on the strength and proportion of the solid layer. Moreover, the 
Fig. 11 Stress distribution of silicone rubber materials with different structures: A pure silicone rubber, $\mathbf{B}$ pure silicone rubber foam, C $3 \mathrm{~L}, \mathbf{D} 5 \mathrm{~L}$, E $7 \mathrm{~L}$, and $\mathbf{F} 9 \mathrm{~L}$
(A)

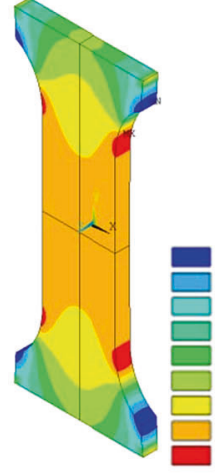

(B)

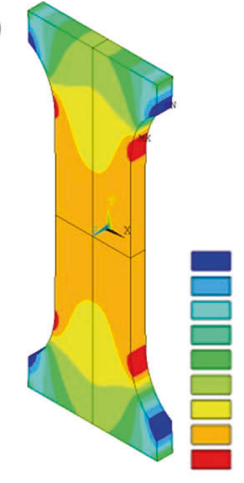

(C)

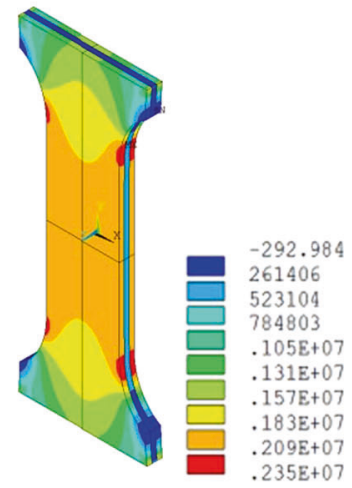

(D)
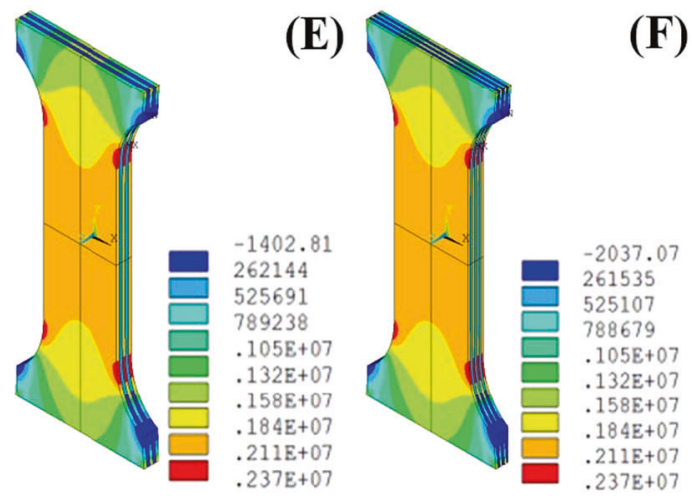

(F)

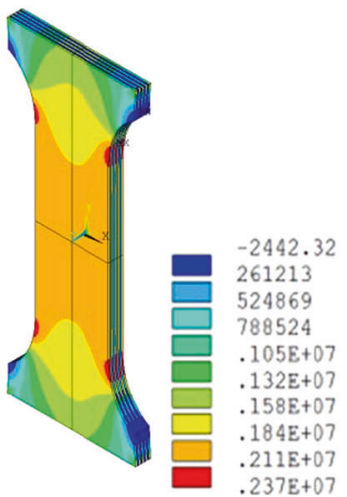

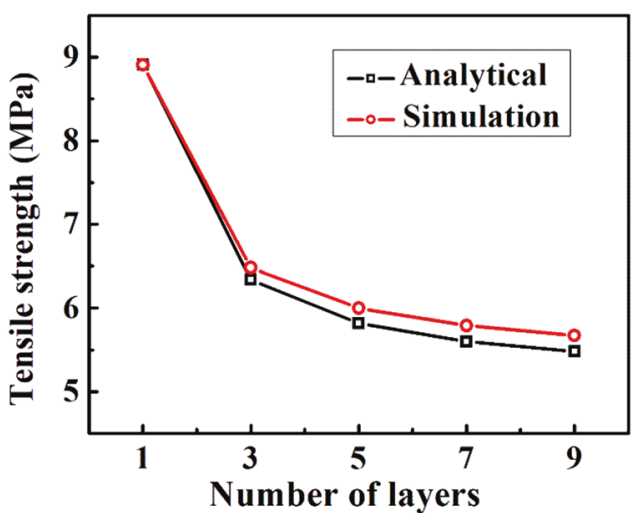

Fig. 12 Comparison of the analytical and simulation results of the fracture stress of the alternating multilayered silicone rubber materials

tensile strength obtained from both theoretical analysis and simulation calculation is higher than the experimental value. It is likely that the theoretical analysis and simulation calculation do not consider the interface effect. The cellular structure of the interface layers exhibits defects during the stretching process, which may lead to the decrease in the tensile strength of the foam/solid alternating multilayered silicone rubber foam. Therefore, through this section of the investigation, an approach to improve the tensile properties of the foam/solid alternating multilayered silicone rubber foam is formulated, to improve the strength and proportion of the solid layer.

\section{The effect of the cellular structure on the compressive properties of silicone rubber materials}

Figure 13 shows the effect of the cell size on the stress-strain curves of silicone rubber foam. From Fig. 13, one can see that the stress-strain curve of the microcellular silicone rubber foam with $18.21 \mu \mathrm{m}$ cells is obviously higher than that of silicone rubber foams with $73.78 \mu \mathrm{m}$ cells. When the foam density is $\sim 0.6 \mathrm{~g} / \mathrm{cm}^{3}$ and the cell volume fraction is $\sim 50 \%$, the compressive stress of the foam with $18.21 \mu \mathrm{m}$ cells is improved by $\sim 20.0 \%$ compared with that of the foam with $73.78 \mu \mathrm{m}$ cells. These investigations [37-40] are in agreement with our results, and they deduce that foams with small cells are stronger than those with larger cells. Furthermore, the smaller cells in the bimodal thermoplastic foam are believed to be the main reason for the significantly elevated compressive properties. When the strain reaches to $40 \%$, the stress sustained by the foam/solid alternating multilayered silicone rubber foam can reaches $0.19 \mathrm{MPa}$, while the stress of the pure silicone rubber foam is only $0.32 \mathrm{MPa}$. The compressive strength of the foam/ solid alternating multilayered silicone rubber improves by $237.5 \%$ compared with that of the pure silicone rubber foam.

However, these investigations [37-40] only prove that the microcellular structure can improve the compressive properties, but they do not give the reason. Therefore, finite 
element analysis is used to obtain the reason for these results. Figure 14 shows the strain distribution of the different cell sizes. The cellular wall of the microcellular silicone rubber foam receives a supporting counterforce during the compressive process. The higher the supporting counterforce is, the stronger the compressive resistance of the microcellular silicone rubber foam. The effect of the cell size on the supporting counterforce of the cellular wall is shown in Fig. 15. One can see that with the reduction in the cell size, the supporting counterforce of the cellular wall increases as shown in Fig. 15. In other words, the small cellular structure leads to a decrease in the radius of curvature, which can obtain an increased supporting counterforce. Thus, the microcellular silicone rubber foam can improve the compressive property.

Figure 16 shows the compressive stress-strain curve of the silicone rubber materials with three different structures. The compression behavior of silicone rubber foam

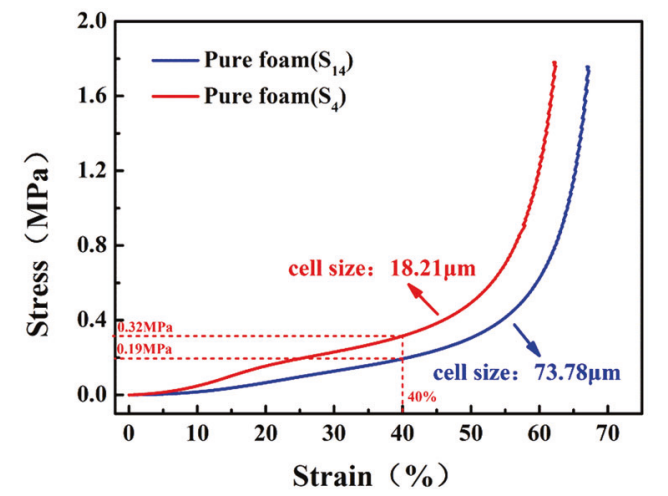

Fig. 13 The effect of the cell size on the stress-strain curve of the silicone rubber foam. The volume fraction of cells is $\left(\mathrm{S}_{4}\right): 49.6 \%$ and $\left(\mathrm{S}_{14}\right): 52.9 \%$ materials is reflected in the compressive stress-strain curve as follows: (1) In the linear elastic stage, the initial stress should become linear. (2) In the plateau stage, with an increase in the compression strain, the stress is maintained in a constant range. (3) In the compaction stage, cell collapse leads to materialization of the foam materials, and the stress and strain return to having a linear relationship. It can be seen from Fig. 16 that the compressive stress-strain curve of the alternating multilayered silicone rubber foam materials and pure foam silicone rubber materials are obviously divided into three regions, which is consistent with the compression behavior of the traditional foam materials described by Gibson et al. [41], but the compressive stress-strain curve of the pure solid silicone rubber is essentially linear. The plateau area for the foam/solid alternating multilayered silicone rubber materials in the compressive stress-strain curves is narrower than that for the pure foam silicone rubber materials and ranges from 15 to $35 \%$. This is because the cell size of the foam layer is small and the deformation required for compaction of the whole material changes slightly. In addition, the compression resistance of the foam/solid alternating multilayered silicone rubber materials is higher than that of the pure silicone rubber foam materials. The foam/solid alternate multilayered structure enables the foam layer to form small cells that improve the compression resistance of the foam materials [42]. When the strain reaches $40 \%$, the stress sustained by the foam/solid alternating multilayered silicone rubber foam reaches $1.08 \mathrm{MPa}$, while the stress of the pure silicone rubber foam is only $0.32 \mathrm{MPa}$. The compressive strength of the foam/solid alternating multilayered silicone rubber is $237.5 \%$ higher than that of the pure silicone rubber foam.
Fig. 14 The effect of the cell size on the strain distribution: A $5 \mu \mathrm{m}, \mathbf{B} 10 \mu \mathrm{m}, \mathbf{C} 20 \mu \mathrm{m}$, and D $50 \mu \mathrm{m}$ (the volume fraction of cells is $50 \%$ for all cases)
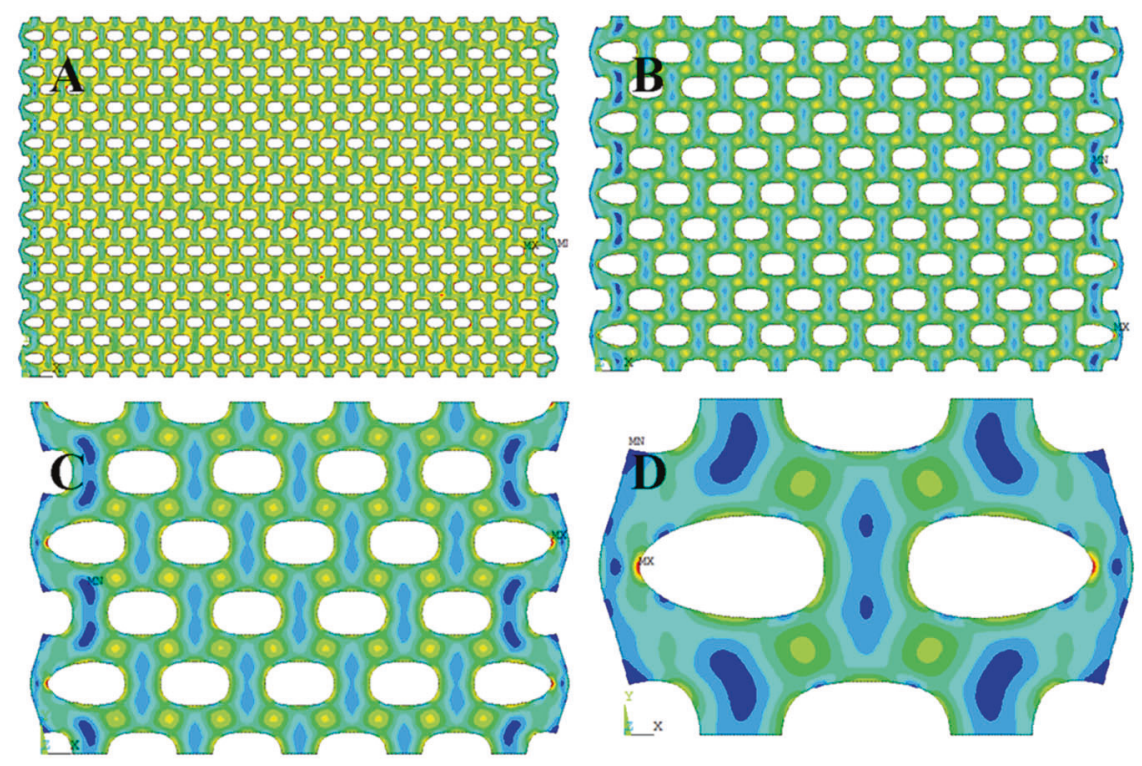


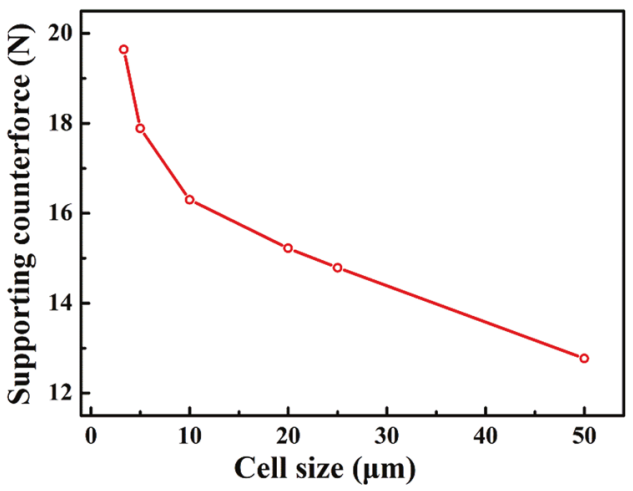

Fig. 15 The effect of the cell size on the supporting counterforce of the cell

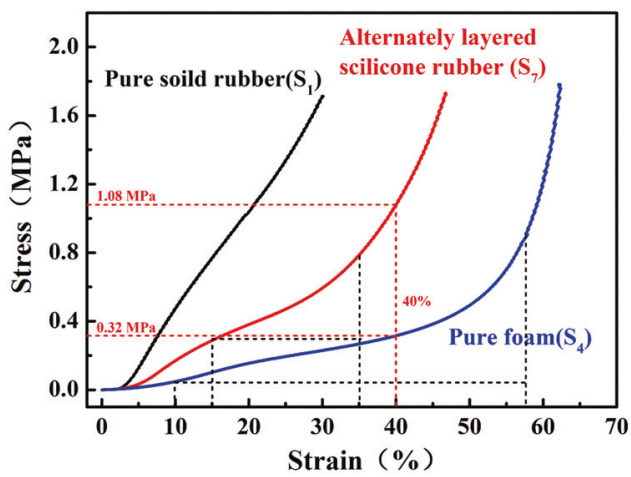

Fig. 16 Stress-strain curves of the silicone rubber materials with different structures

\section{Conclusion}

In this paper, the microcellular structure of silicone rubber foam is controlled by adjusting the viscoelasticity of the silicone rubber matrix, and foam/solid alternating multilayered silicone rubber materials are successfully constructed by means of layer-by-layer stacking and supercritical foaming. By introducing solid layers into the silicone rubber foam materials, the cellular growth is restricted, and the foam layer forms a small cellular structure. The tensile strength of the foam/solid alternating multilayered silicone rubber materials reaches $5.39 \mathrm{MPa}$, which is $46.1 \%$ higher than that of the pure silicone rubber foam. Moreover, when the compressive strain reaches $40 \%$, the stress of the foam/solid alternating multilayered silicone rubber materials reaches $1.08 \mathrm{MPa}$, which is $237.5 \%$ higher than that of the pure silicone rubber foam. It may therefore be possible to improve the tensile properties of the foam/solid alternating multilayered silicone rubber foam by increasing the strength and proportion of the solid layer.

Acknowledgements This work is supported by the National Natural Science Foundation of China (No. 51773186).

\section{Compliance with ethical standards}

Conflict of interest This work is supported by the National Natural Science Foundation of China (No. 51773186). The authors declare that they have no other conflict of interest.

Publisher's note Springer Nature remains neutral with regard to jurisdictional claims in published maps and institutional affiliations.

Open Access This article is licensed under a Creative Commons Attribution 4.0 International License, which permits use, sharing, adaptation, distribution and reproduction in any medium or format, as long as you give appropriate credit to the original author(s) and the source, provide a link to the Creative Commons license, and indicate if changes were made. The images or other third party material in this article are included in the article's Creative Commons license, unless indicated otherwise in a credit line to the material. If material is not included in the article's Creative Commons license and your intended use is not permitted by statutory regulation or exceeds the permitted use, you will need to obtain permission directly from the copyright holder. To view a copy of this license, visit http://creativecommons. org/licenses/by/4.0/.

\section{References}

1. Shih RS, Kuo SW, Chang FC. Thermal and mechanical properties of microcellular thermoplastic SBS/PS/SBR blend: effect of crosslinking. Polymer. 2011;52:752-9.

2. Nalawade SP, Picchioni F, Janssen LPBM. Supercritical carbon dioxide as a green solvent for processing polymer melts: processing aspects and applications. Prog Polym Sci. 2006;31:19-43.

3. Sauceau M, Fages J, Common A, Nikitine C, Rodier E. New challenges in polymer foaming: a review of extrusion processes assisted by supercritical carbon dioxide. Prog Polym Sci. 2011; 36:749-66.

4. Song L, Lu A, Feng P, Lu Z. Preparation of silicone rubber foam using supercritical carbon dioxide. Mater Lett. 2014;121:126-8.

5. Yue Y, Zhang H, Zhang Z. Polymer-filler interaction of fumed silica filled polydimethylsiloxane investigated by bound rubber. Compos Sci Technol. 2013;86:1-8.

6. Liu B, Wang P, Ao Y. Effects of combined neutron and gamma irradiation upon silicone foam. Radiat Phys Chem. 2017;133:31-6.

7. Wen J, Li Y, Zuo Y. Preparation and characterization of nanohydroxyapatite/silicone rubber composite. Mater Lett. 2008;62: 3307-9.

8. Landrock AH. Handbook of plastic foams. New Jersey: Noyes Publications; 1995.

9. Hao Y, Wang K, Zhao Y. Fabrication of silicone rubber foam with tailored porous structures by supercritical $\mathrm{CO}_{2}$. Macromol Mater Eng. 2017;302:1-10.

10. Liu T, Lei Y, Zhang F, Guo S, Luo S. Microcellular crosslinked silicone rubber foams: influence of nucleation agent (polyhedral oligomeric silsesquioxane) on the rheological, vulcanizing, cell morphological properties. Polym-Plast Technol Eng. 2017;57:1-11.

11. Zhang C, Liu L, Zhang Z, Pal K, Kim JK. Effect of silica and silicone oil on the mechanical and thermal properties of silicone rubber. J Macromol Sci Part B: Phys. 2011;50:1144-53.

12. Bai J, Liao X, Huang E, Luo Y, Yang Q, Li G. Control of the cell structure of microcellular silicone rubber/nanographite foam for enhanced mechanical performance. Mater Des. 2017;133:288-98.

13. Luo S, Ding G, Dai B, Yang M, Liu F. Study on the cell structure and mechanical properties of methyl vinyl silicone rubber foam materials. Adv Mat Res. 2014;1004-1005:297-306. 
14. Xiang B, Jia Y, Lei Y, Zhang F. Mechanical properties of microcellular and nanocellular silicone rubber foams obtained by supercritical carbon dioxide. Polym J. 2019;51:559-68.

15. Park ES. Mechanical properties and antibacterial activity of peroxide-cured silicone rubber foams. J Appl Polym Sci. 2008; 110:1723-9.

16. Gao Y, Gao X, Li J, Guo S. Microwave absorbing and mechanical properties of alternating multilayer carbonyl iron powder-poly (vinyl chloride) composites. J Appl Polym Sci. 2017;135:45846.

17. Gao W, Zheng Y, Shen J, Guo S. Electrical properties of polypropylene-based composites controlled by multilayered distribution of conductive particles. ACS Appl Mater Interfaces. 2015;7:1541-9.

18. Zheng Y, Dong R, Shen J, Guo S. Tunable shape memory performances via multilayer assembly of thermoplastic polyurethane and polycaprolactione. ACS Appl Mater Interfaces. 2016;8:1371-80.

19. Zheng Y, Ji X, Yin M, Shen J, Guo S. A strategy for fabricating multiple shape memory polymeric materials via the multilayer assembly of co-continuous blend. ACS Appl Mater Interfaces. 2017;9:32270-9.

20. Yi L, Luo S, Shen J, Guo S, Sue HJ. Bioinspired polylactide based on the multilayer assembly of shish-kebab structure: a strategy for achieving balanced performances. ACS Sustain Chem Eng. 2017; 5:3063-73.

21. Mi H, Salick MR, Jing X, Jacques BR, Crone WC, Peng X, et al. Characterization of thermoplastic polyurethane/polylactic acid (TPU/PLA) tissue engineering scaffolds fabricated by microcellular injection molding. Mater Sci Eng: C. 2013;33:4767-76.

22. Zhang X, Xu Y, Zhang X, Wu H, Shen J, Chen R, et al. Progress on the layer-by-layer assembly of multilayered polymer composites: strategy, structural control and applications. Prog Polym Sci. 2018;10:1-32.

23. Zhao T, Wu H, Guo S, Sun X, Liang W. Morphology and properties of polypropylene foaming sheet with alternating multilayered structure. Polym-Plast Technol Eng. 2015;54:899-906.

24. Jiang X, Yang Z, Wang Z, Zhang F, You F, Yao C. Preparation and sound absorption properties of a barium titanate/nitrile butadiene rubber-polyurethane foam composite with multilayered structure. Materials. 2018;11:474.

25. Zhou D, Xiong Y, Yuan H, Luo G, Zhang J, Shen Q, et al. Synthesis and compressive behaviors of PMMA microporous foam with multi-layer cell structure. Compos Part B: Eng. 2019; 165:272-8.
26. Ranada AP, Hiltner A, Baer E. Structure-property relationships in coextruded foam/film microlayers. J Cell Plast. 2004;40:497-507.

27. Ozturk UE, Anlas G. Finite element analysis of expanded polystyrene foam under multiple compressive loading and unloading. Mater Des. 2011;32:773-80.

28. Arefmanesh A, Advani SG, Michaelides EE. A numerical study of bubble growth during low pressure structural foam molding process. Polym Eng Sci. 1990;30:1330-7.

29. Arefmanesh A, Advani SG. Nonisothermal bubble growth in polymeric foams. Polym Eng Sci. 1995;35:252-60.

30. Jia Y, Xiang B, Zhang W, Liu T. Microstructure and properties of microcellular silicone rubber foams with improved surface quality. Polym J. 2019. https://doi.org/10.1038/s41428-019-0249-5.

31. Colton JS, Suh NP. The nucleation of microcellular thermoplastic foam with additives: Part II: experimental results and discussion. Polym Eng Sci. 1987;27:493-9.

32. Colton JS, Suh NP. Nucleation of microcellular foam: theory and practice. Polym Eng Sci. 1987;27:500-3.

33. Youn JR, Suh NP. Processing of microcellular polyester composites. Polym Compos. 1985;6:175-80.

34. Hong IK, Lee S. Microcellular foaming of silicone rubber with supercritical carbon dioxide. Korean J Chem Eng. 2014;31:166-71.

35. Yang Q, Yu H, Song L, Lei Y, Zhang F, Lu A, et al. Solid-state microcellular high temperature vulcanized (HTV) silicone rubber foam with carbon dioxide. J Appl Polym Sci. 2017;134:44807.

36. Sha Y, Zhang C, Li J, Luo S. Effects of cell structure on properties of silicone rubber foam material. Mater Mech Eng. 2013;37:25-28.

37. Ma Z, Zhang G, Yang Q, Shi X, Liu Y. Mechanical and dielectric properties of microcellular polycarbonate foams with unimodal or bimodal cell-size distributions. J Cell Plast. 2015;51:307-27.

38. Bao J, Liu T, Zhao L, Hu G. A two-step depressurization batch process for the formation of bi-modal cell structure polystyrene foams using scCO2. J Supercrit Fluids. 2011;55:1104-14.

39. Zhang C, Zhu B, Li D, Lee L. Extruded polystyrene foams with bimodal cell morphology. Polymer. 2012;53:2435-42.

40. Bao J, Weng G, Zhao L, Liu Z, Chen Z. Tensile and impact behavior of polystyrene microcellular foams with bi-modal cell morphology. J Cell Plast. 2014;50:381-93.

41. Gibson LJ, Ashby MF. Cellular solids structure and properties. Camb Univ Press. 1988;33:487-8.

42. Choi JS, Chun BC, Lee SJ. Effect of rubber on microcellular structures from high internal phase emulsion polymerization. Macromol Res. 2003;11:104-9. 